\title{
Aluminum Plant. Load Modeling for Stability Studies.
}

\author{
J.L. Agüero \\ Member IEEE \\ IITREE-LAT. Facultad de Ingeniería \\ Universidad Nacional de La Plata \\ (1900) 48 y 116. La Plata. Argentina
}

\author{
M. Beroqui \\ Prof. Ppal. CIC \\ IITREE-LAT. Facultad de Ingenieria \\ Universidad Nacional de La Plata \\ (1900) 48 y 116. La Plata. Argentina
}

\author{
S. Achilles \\ IITREE-LAT. Facultad de Ingenieria \\ Universidad Nacional de La Plata \\ (1900) 48 y 116. La Plata. Argentina
}

\begin{abstract}
The "Sistema Eléctrico Patagónico Interconectado (SEPI)" is an electric system that involves the Argentina south region. This electric system is isolated from the other one in the north of the country. The $60 \%$ of its load is consumed by an aluminum production plant consisting of two $160 \mathrm{MW}$ series of 200 electrolytic cells each one. Dynamic and transient stability studies carried out over this system, taking into account present and future situations, with load and generation grown at the aluminum plant and in the remaining system, require adequate modeling of this particular load. Tests and simulations carried out to obtain the electrolytic process load model are described. Statistical behavior of the aluminum plant load variations is analyzed, to estimate the spinning reserve in the system. By the way, available load shedding mechanisms at the aluminum plant, as a system control element, were tested and the results are analyzed.
\end{abstract}

Keywords: Load modeling. Power System Dynamic Stability. Power System Transient Stability. Spinning Reserve. Load shedding.

\section{INTRODUCTION}

The Argentine Republic has two separated electrical systems. The "Sistema Eléctrico Argentino de Interconexión" (SADI), the greatest system, is located in the center and north of the country, with interconnections to the neighboring countries Uruguay and Brazil. The "Sistema Eléctrico Patagónico Interconectado" (SEPI), the smallest one, is located in the country south or "Patagonia" region.

The SEPI is relatively small; its load peak is approximately $600 \mathrm{MW}$. It has a $470 \mathrm{MW}$ hydraulic power station connected, through two $330 \mathrm{kV}$ lines of $550 \mathrm{~km}$, to an industrial plant that produces aluminum by electrolysis. The rest of the SEPI has $1305 \mathrm{~km}$ of $132 \mathrm{kV}$ lines, with radials distributed load and generation. Motors in petroleum deposits compose an important part of this demand.

The aluminum plant has two electrolytic series and its own electrical generation by means of gas turbines.

In Fig 1 is a SEPI simplified scheme, showing the present situation and future enlargement of the aluminum plant.

Abstract ID Number: 99 SM 099

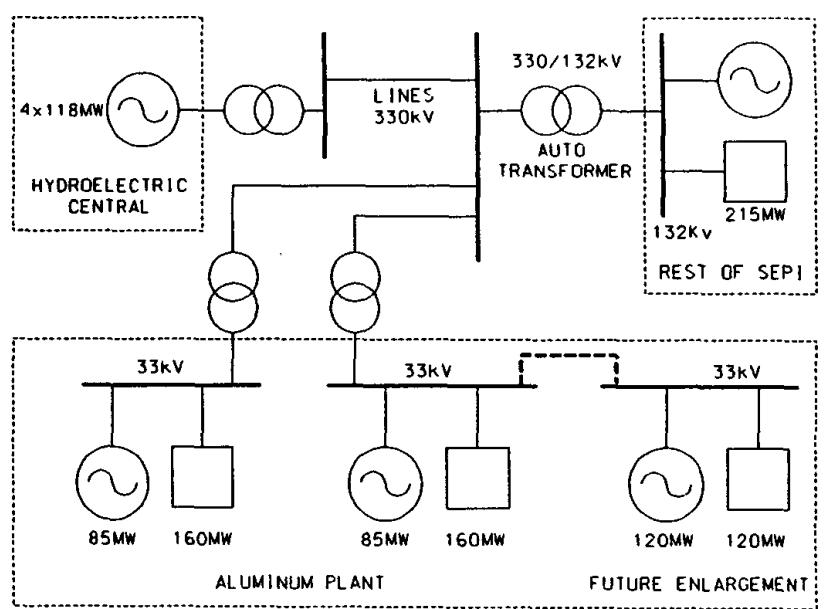

Fig. 1: SEPI Simplified scheme.

The electrolytic series demand and the installed generation powers in the aluminum plant and in the hydraulic plant are indicated.

It is required to perform stability studies for the present situation, for the out of service of the hydraulic power plant due to programmed maintenance and for future situations that contemplate the extensions of generation and demand in the SEPI.

The load modeling must be taken into account, in addition to the generator, voltage and speed regulators modeling ([1], [2] and [3]).

As the aluminum plant load constitute approximately $60 \%$ of the SEPI load, it is very important to know precisely its dynamic behavior. Any dynamic study of the SEPI must contemplate the particular characteristics of this load to achieve reliable results.

The purpose of this work is to describe the tests and the measurements made on one of the two series of the aluminum plant and to report the determination, based on the field tests, of a model able to represent the dynamic characteristics of the electrolytic series.

The methodology consists in proposing a model of the series and their control systems, and to adjust the model parameters in order to obtain a good agreement between the measured signals and the simulated ones.

\section{SERIES OPERATION}

In Fig. 2 is a schematic diagram of the series AC-DC conversion system. Each of the four rectifiers groups that feeds a series is connected to an autotransformer with tap changing under load. A group has two subgroups consisting 